\title{
SJRM \\ Comparison of the effectiveness of oral Tadalafil and neuromuscular biofeedback of the pelvic floor muscles along with oral Tadalafil in the treatment of erectile dysfunction in men
}

\begin{tabular}{l} 
ARTICLE INFO \\
Article Type \\
Analytical cross-sectional study \\
\hline \\
Authors \\
Mehri Nejat MD ${ }^{1,2 *}$, \\
Sajjad Qalunya Fashalami MSc ${ }^{3}$, \\
Habib Rashadi MD \\
Sarem Fertility and Infertility \\
${ }^{1}$ Research Center (SAFIR), \\
Sarem Women's Hospital, \\
Iran University of Medical \\
Sciences (IUMS), Tehran, Iran \\
${ }^{2}$ Nejat Sexual Disorders \\
Center Iran University of \\
Medical Science, Tehran, Iran \\
${ }^{3}$ Faculty of Educational \\
Sciences and Psychology, \\
University of Tehran, Tehran, \\
Iran On \\
${ }^{4}$ Tehran Orthopedic and \\
Physiotherapy Center \\
\hline
\end{tabular}

*Corresponding Author

Address: Agape Sexual Disorders Center \& Sarem Women Hospital, Basij Square, Phase 3, EkbatanTown, Tehran, Iran. Postal code: 1396956111

Phone: +98 (21) 44670888 \& +98 (21) 46040339

Fax: +98 (21) 44670432

mehrinejat8194@gmail.com

\section{ABSTRACT}

Introduction: The pelvic floor muscles are normally active in erectile function. Therefore, it is assumed that weak pelvic floor muscles cause erectile dysfunction and on the other hand, normal function of pelvic floor muscles in penile blood supply and erectile function plays an important role.

Aim: The aim of the present study was to compare the efficacy of oral Tadalafil and neuromuscular biofeedback of pelvic floor muscles along with oral Tadalafil in the treatment of erectile dysfunction in men.

Methodology: The sample consisted of 60 men with erectile dysfunction, with a mean age of 43.66 years, referred to the Agape Sexual Disorders Center in Tehran and Sarem Hospital. Of these, 30 patients were randomly assigned to the intervention group and were treated with neuromuscular biofeedback for 5 weeks and took $5 \mathrm{mg}$ of Tadafil daily, and 30 patients as a control group used $5 \mathrm{mg}$ of Tadafil daily. Evaluation was performed by interview and clinical examination, as well as International Erectile Performance Index Questionnaire (IIEF5).

Results: In the fifth week after treatment, both intervention and control groups showed a significant difference $(\mathrm{P}<0.001)$ in increasing the score of the International Erectile Performance Index (IIEF5) from pre-test to post-test. But only in the intervention group, the increase in pelvic floor muscle strength was significant $(\mathrm{P}<0.001)$. On the other hand, there was a significant difference between the two groups in erectile function and pelvic floor muscle strength.

Conclusion: Based on the findings of the study, it can be concluded that neuromuscular biofeedback in combination with Tadalafil is an effective treatment for men with erectile dysfunction.

Keywords: Erectile dysfunction, Tadalafil, Neuromuscular biofeedback, Pelvic floor muscles.

\section{Article History}

Received: September 19, 2019

Accepted: December 06, 2019

e Published: December 13, 2020

Copyright(C) 2020, ASP Ins. This open-access article is published under the terms of the Creative Commons Attribution-Noncommercial 4.0 International License which permits Share (copy and edistribute the material in any medium or format) and Adapt (remix, transform, and build 


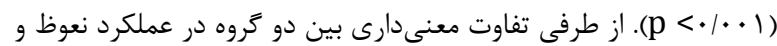

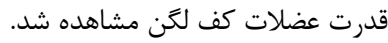

نتيجه كيرى: با توجه به يافته هاى بدست امده از تحقيق مى توان نتيجه كيرى كرد كه بيوفيدبك نوروماسكولار در تركيب با تادالافيل يك درمان مؤثر براى مردان با اختلال نعوظ است. كليد وازهها: اختلال نعوظ، تادالافيل، بيوفيدبك نوروماسكولار، عضلات كف

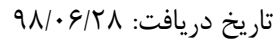
تاريخ خذيرش:

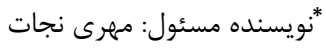

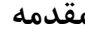
اختلال نعوظ به معناى عدم موفقيت در دستيابى و حفظ نعوظ كافى براى

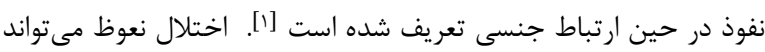

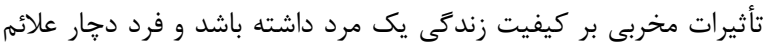

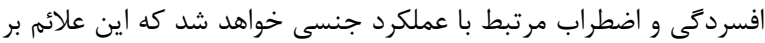

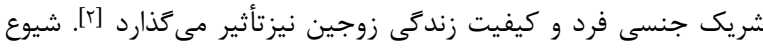

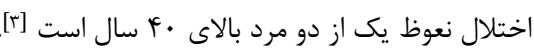

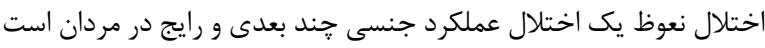

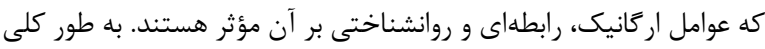

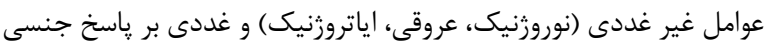

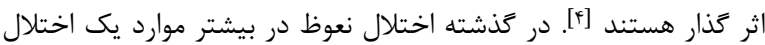

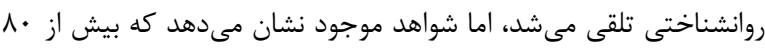

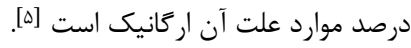

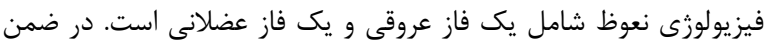

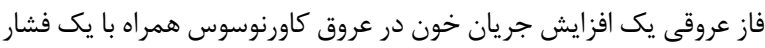

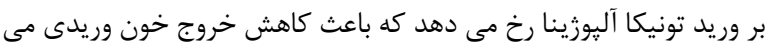

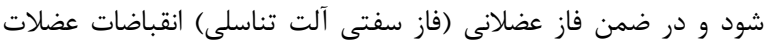

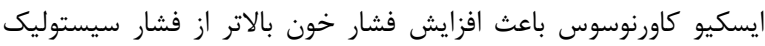

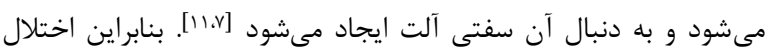

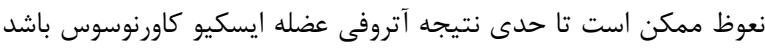

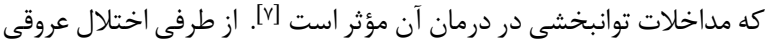

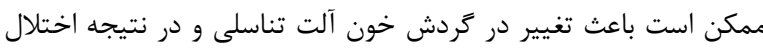

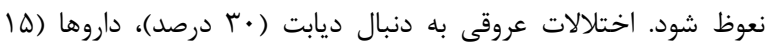

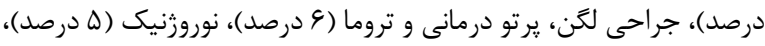

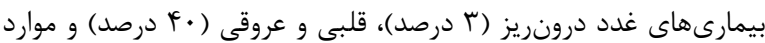
ديكر (ا درصد) ايجاد مى شود [بان.

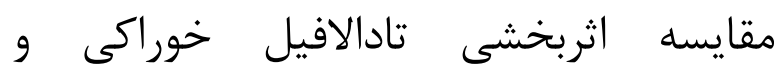
بيوفيدبك نوروماسكولار عضلات كف لكن همراه با تادالافيل خوراكى در درمان اختلال

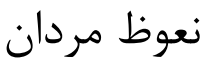

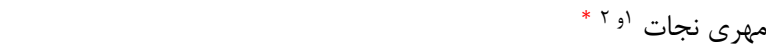
' مركز تحقيقات بارورى و نابارورى صارم، بيمارستان فوق تخصصى صارم، دانشخاه علوم يزشكى ايران، تهران، ايران

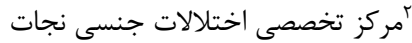

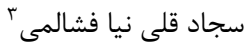

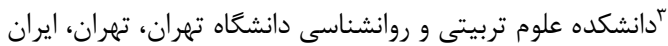

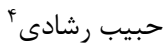
r مركز ارتويدى و فيزيوترابى تهران ، تهران، ايران

جكيده مقدمه: عضلات كف لتَن در عملكرد نعوظ به طور نرمال فعال هستند. بنابراين فرض بر اين است كه عضلات ضعيف كف لكَن عامل اختلال نعوظ

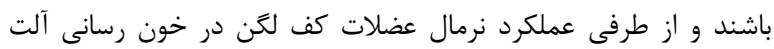

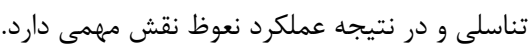
هدف: هدف از مطالعه حاضر مقايسه اثربخشى تادالافيل خوراكى و

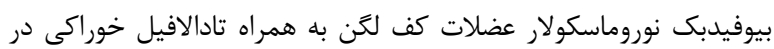

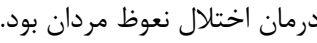

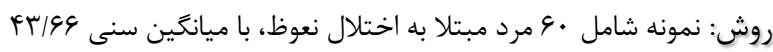
سال مراجعه كننده به مركز اختلالات جنسى آكايه تهران و بيمارستان

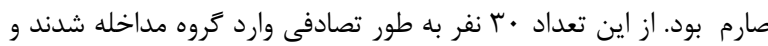

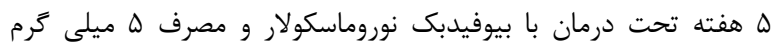

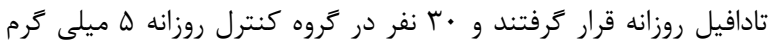

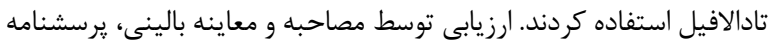
شاخص بين المللى عملكرد نعوظ (IIEF5) انجام شد.

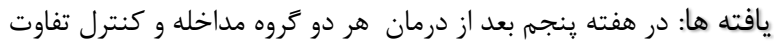

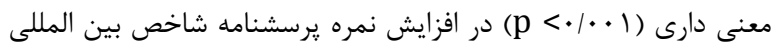

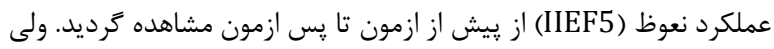

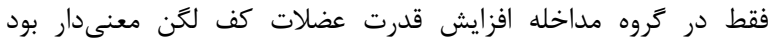


اختلال نعوظ مردان جهت رسيدن به نتيجه درمانى كامل و سريعتر

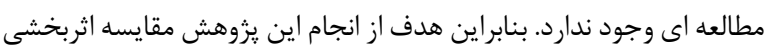

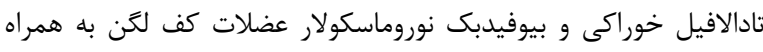

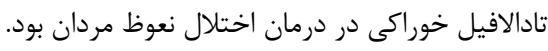

\section{مواد و روشها}

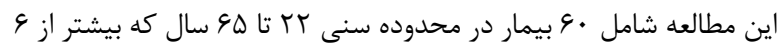

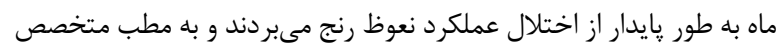

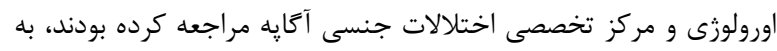

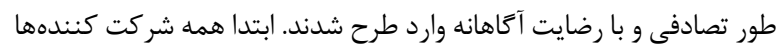

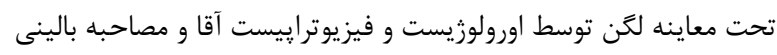

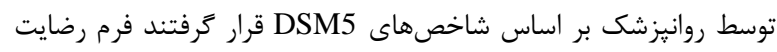

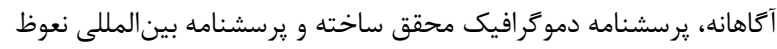

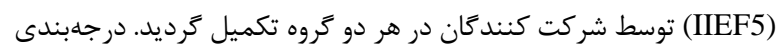

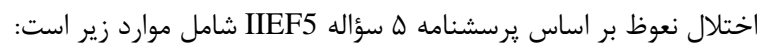

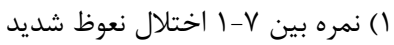

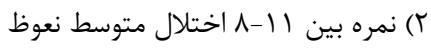

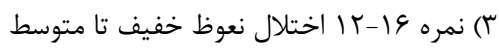

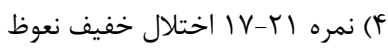

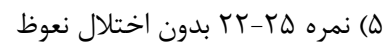

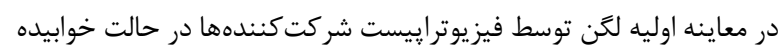

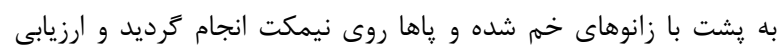

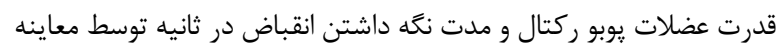

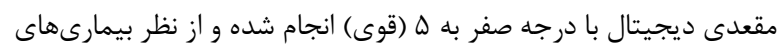

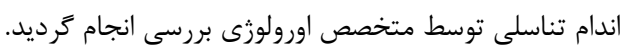

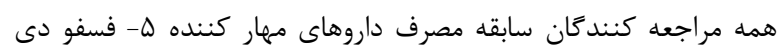

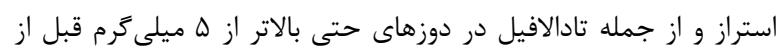

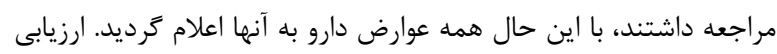

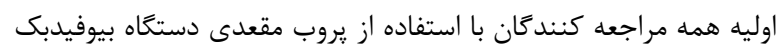

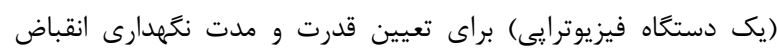

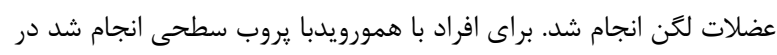

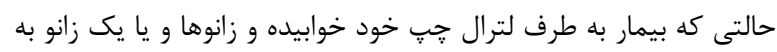

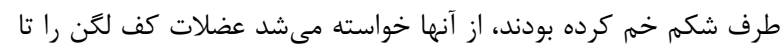

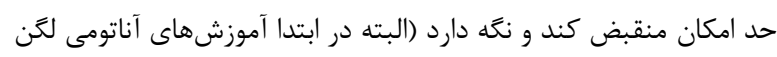

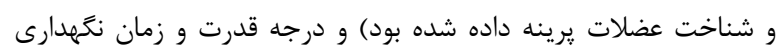

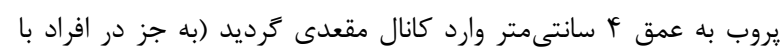

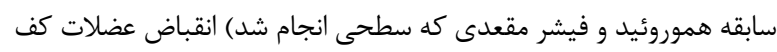

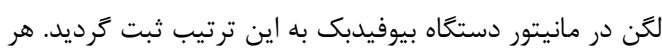

از مداخلات درمانى با تهاجم كمتر در بهبود عملكرد نعوظ علاوه بر اصلاح

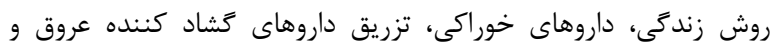

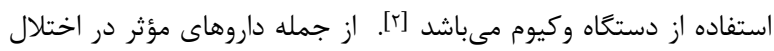
نعوظ مهار كننده هاى فسفو دى استراز (PDE5I) هستند كه به عندان آندان

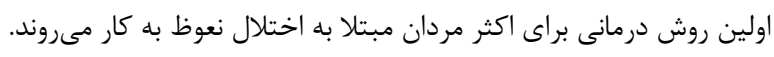

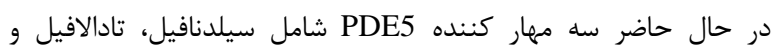

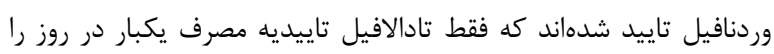

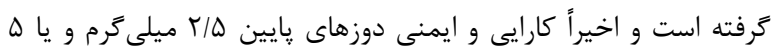

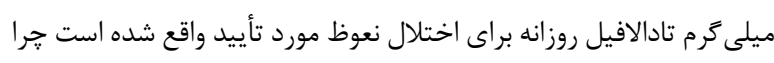

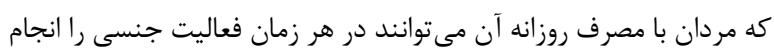

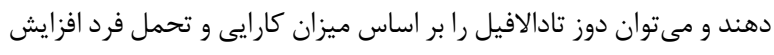

داد [^]. تادالافيل باعث مهار آنزيم شماره ه فسفودىاستراز خاص CGMP شده و

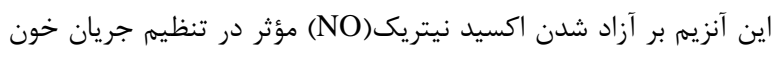

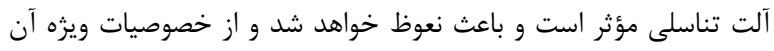

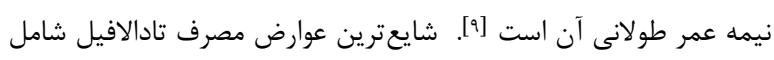

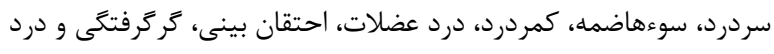

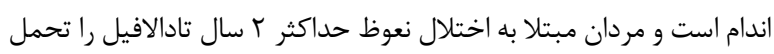

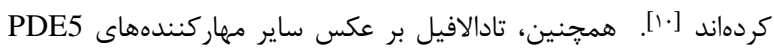

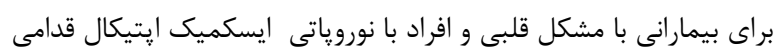

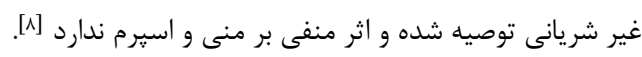

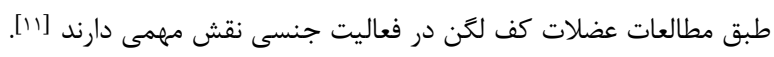

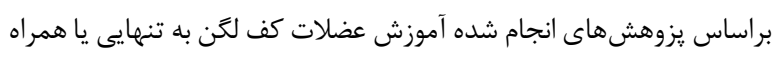

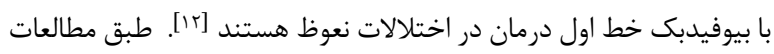

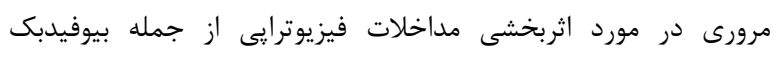

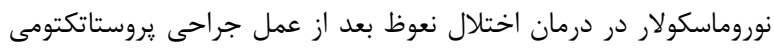

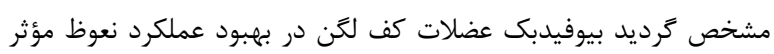

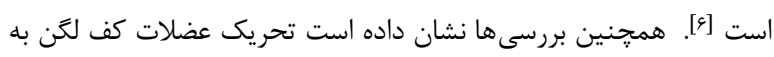

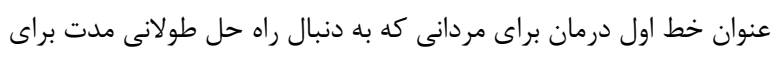

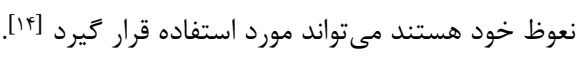

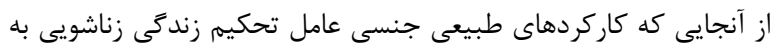

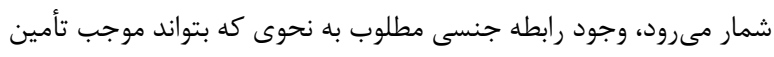

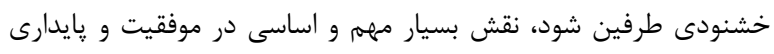

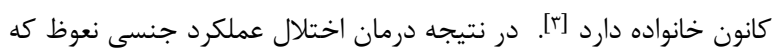

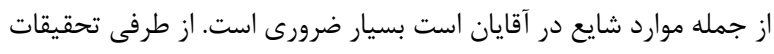

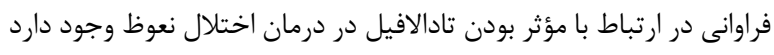

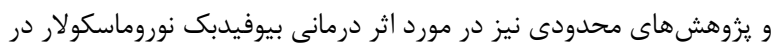

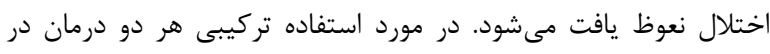

'phosphodiesterase 
در يزوهش حاضر از روش هارى هاى آمارى توصيفى در سطح شاخص هاى

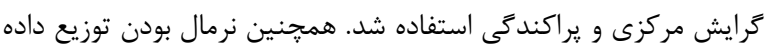

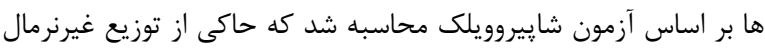

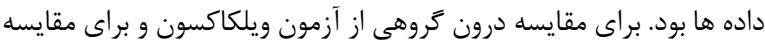

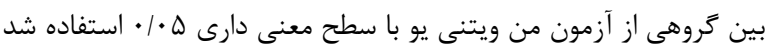

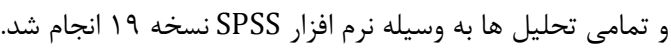

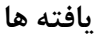

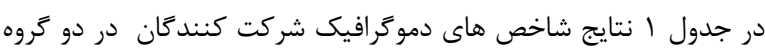

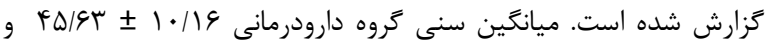

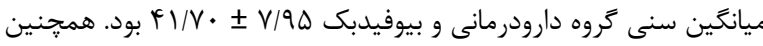

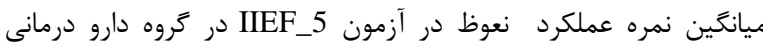

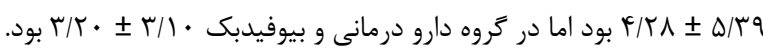

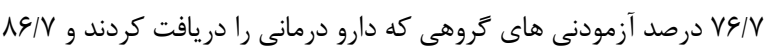

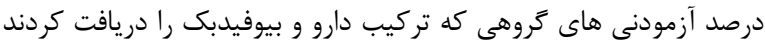

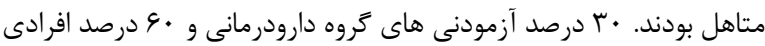

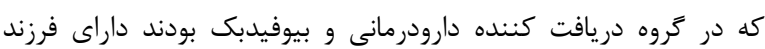

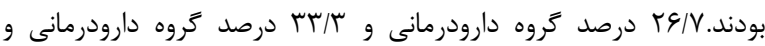

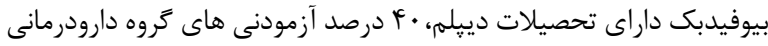

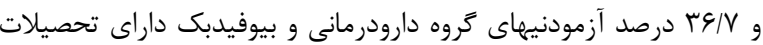

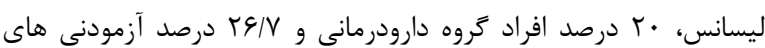

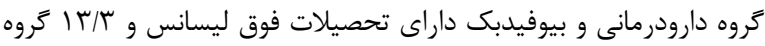

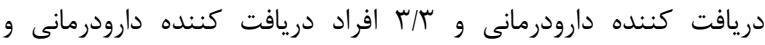

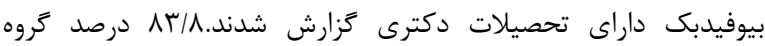

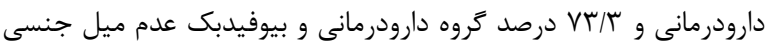

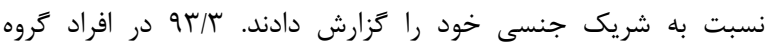

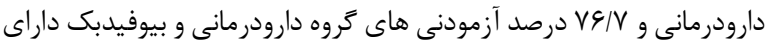

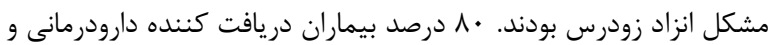

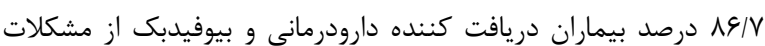

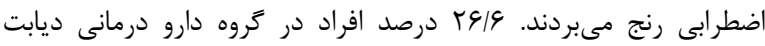

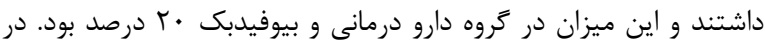

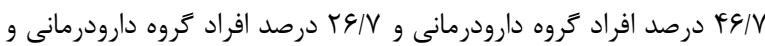

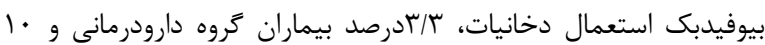

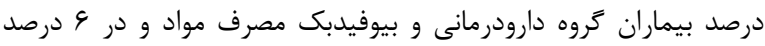

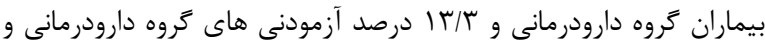
بيوفيدبك مصرف مشروبات الكلى كزارش شدر.

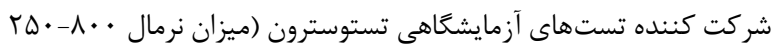

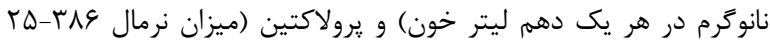

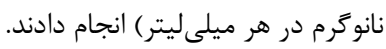

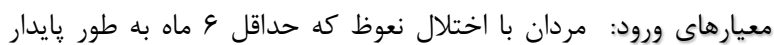
مشكل در تحريك و نتحهداشتن آلت تناسلى داشتند.

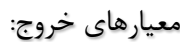

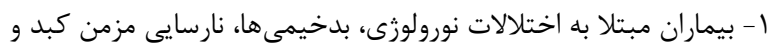

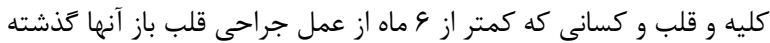

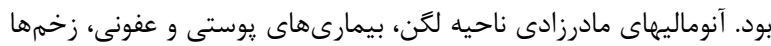

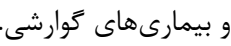

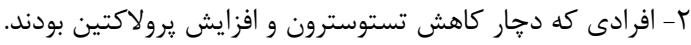

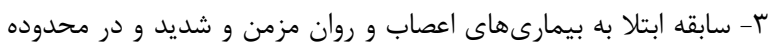

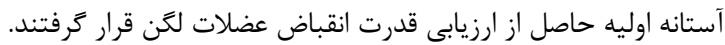

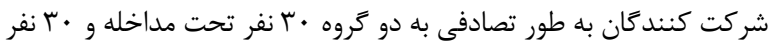

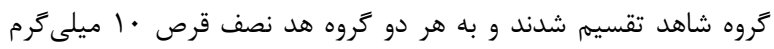

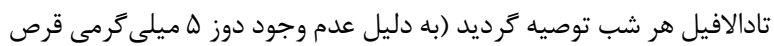

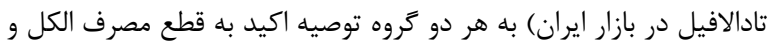

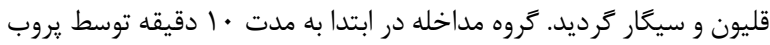

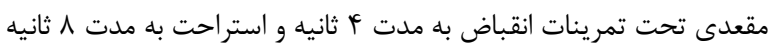

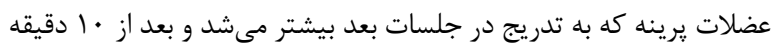

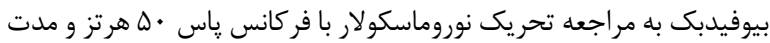

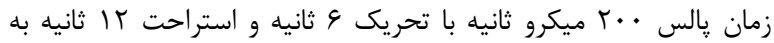

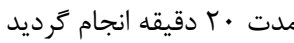

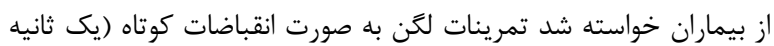

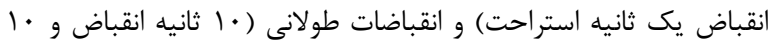

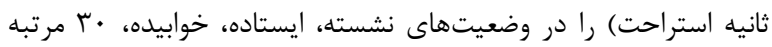

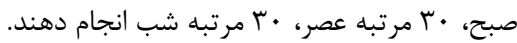

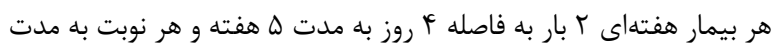

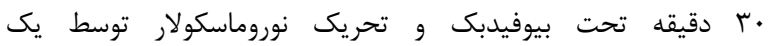

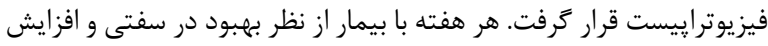

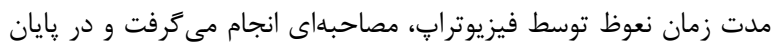

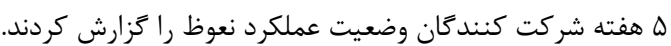

1- پاسخ كامل: باز گشت به عمكرد جنسى رضايتبخش با وقوع نعوظ كافى براى نفوذ r- اساسخ بهبود يافته: بيشرفت در مدت زمان با سفتى نعوظ كزارش داده اما اين بهبود كافى براى رابطه جنسى رضايتبخش كافى بهى بردي

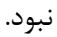
r- ع عدم موفقيت: بهبود جشمخيرى در عمكرد نعوظ خود گزارش نود نمى نهد.

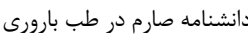




\begin{tabular}{|c|c|c|c|c|c|c|c|c|}
\hline \multicolumn{4}{|c|}{ داور درمانى و بيوفيدبك } & \multicolumn{4}{|c|}{ دارو درمانى } & \multirow{3}{*}{ متغير/آروه } \\
\hline \multicolumn{2}{|c|}{ يس آزمون } & \multicolumn{2}{|c|}{ بيش آزمون } & \multicolumn{2}{|c|}{ يس آزمون } & \multicolumn{2}{|c|}{ بيش آزمون } & \\
\hline معيار & ميانكين & معيار & ميانكين & معيار & ميانكين & معيار & ميانكين & \\
\hline 9191 & $r T / q$. & $r / . r$ & $F / v$. & $r / \Delta q$ & V/G. & $r / .$. & $r / V$ & نعملكرد \\
\hline IV/ND & $\varphi V / \Delta$. & $r / q r$ & IN/VE & $V / \cdot r$ & Tr/AT & $V / q v$ & $r / F$. & كف عضلات \\
\hline
\end{tabular}

همانكَونه كه در جدول r مشاهده مىشود در ميانگين متغيرهاى قدرت

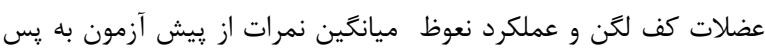

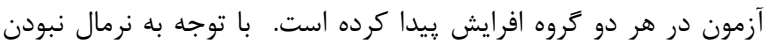

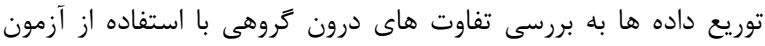

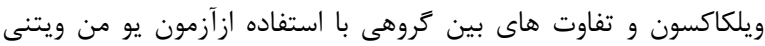

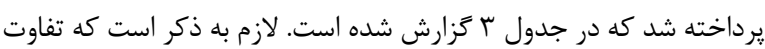

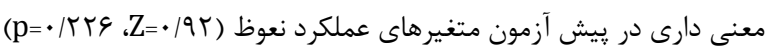

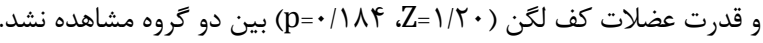

جدول ب. تفاوت هاى درون كروهى در قدرت عضلات كف لكن و عملكرد

\begin{tabular}{|c|c|c|c|c|}
\hline \multicolumn{2}{|c|}{ قدرت عضلات لتن } & \multicolumn{2}{|c|}{ عملكرد نعوظ } & \multirow[t]{2}{*}{ كروه/ متغير } \\
\hline Sig & $\mathrm{Z}$ & sig & $\mathrm{Z}$ & \\
\hline$\cdot \mid \Delta \Delta F$ & $.109 T$ & $.1 \cdot .1$ & $f / r \wedge q$ & دارو درمانى \\
\hline$\cdot 1 \cdot \cdot 1$ & $\mathrm{f} / \mathrm{A} .$. & $.1 . .1$ & F/VAV & داور درمانى و \\
\hline
\end{tabular}

نتايج آزمون ويلكاكسون نشان داد كه تفاوت معنى دارى از پِيش آزمون تا

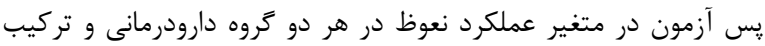

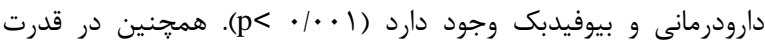

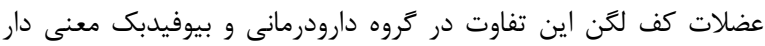

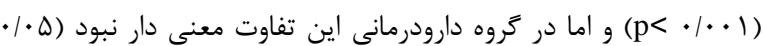

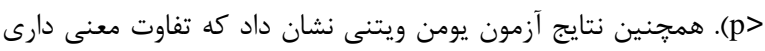

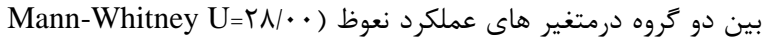

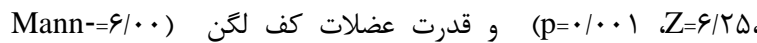

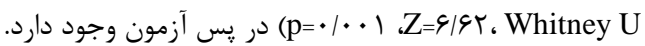

\begin{tabular}{|c|c|c|c|c|c|}
\hline \multicolumn{2}{|c|}{ داور درمانى و } & \multicolumn{2}{|c|}{ دارو درمانى } & \multirow[t]{2}{*}{ وضعيت } & \multirow[t]{2}{*}{ شاخص } \\
\hline درصد & تعداد & درصد & تعداد & & \\
\hline$\Lambda 9 / V$ & TG & $V G / V$ & זr & متاهل & \multirow{2}{*}{ تاهل } \\
\hline r & f & r/r & V & مجرد & \\
\hline f. & IT & v. & rI & خير & \multirow{2}{*}{ فرزند } \\
\hline c. & 11 & r. & 9 & بله & \\
\hline r/r & $1 \cdot$ & re/V & $\wedge$ & دييله & \multirow{4}{*}{ تحصيلات } \\
\hline re/V & 11 & f. & Ir & ليسانس & \\
\hline T\&/V & $\Lambda$ & $r$. & 4 & فوق & \\
\hline r/r & 1 & r & f & دكترى & \\
\hline T\&/V & $\wedge$ & $19 / V$ & $\Delta$ & خير & \multirow{2}{*}{ عدم ميل } \\
\hline$V \mu / r$ & Tt & $\Lambda r / \Lambda$ & $r \Delta$ & بله & \\
\hline & v & s/V & r & خير & \multirow{2}{*}{ زود انزالى } \\
\hline$V G / V$ & זr & r & $r \Lambda$ & بله & \\
\hline r & f & $r$. & 4 & خير & \multirow{2}{*}{ اضطراب } \\
\hline$\Lambda \& / V$ & TE & $\wedge$. & TF & بله & \\
\hline$\wedge$. & TY & $V \Psi / \mu$ & rT & خير & \multirow{2}{*}{ ديابت } \\
\hline$r$. & $\varepsilon$ & re/V & $\wedge$ & بله & \\
\hline$V \mu / r$ & rT & $\Delta r / r$ & 19 & خير & \multirow{2}{*}{ سيكًار } \\
\hline$r \& / V$ & $\wedge$ & $\varphi g / V$ & If & بله & \\
\hline 9 . & TV & $99 / V$ & rq & خير & \multirow{2}{*}{ مصرف مواد } \\
\hline 1 . & r & $r / r$ & 1 & بله & \\
\hline$\Lambda 9 / V$ & rG & $\wedge$. & TF & خير & \multirow{2}{*}{ مشرف } \\
\hline r & f & $r$. & 4 & بله & \\
\hline
\end{tabular}

در ادامه يزوهش به بررسى نتايج توصيفى متغيرهاى وابسته قدرت عضلات

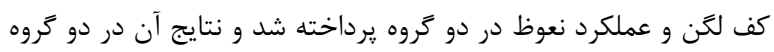

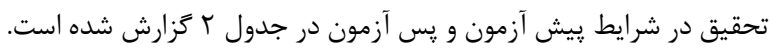


درمانى تهاجمىتر مانند وكيوم، تزريق داخل آلت يا حتى استفاده از جراحى

و يروتزها هستند توصيه كرد.

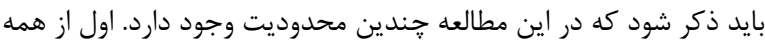

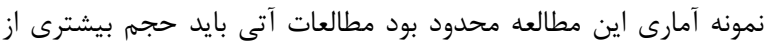

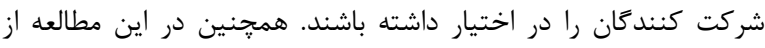

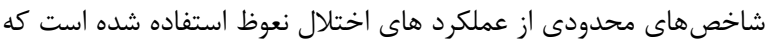

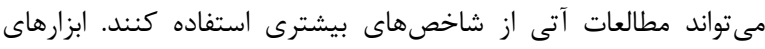

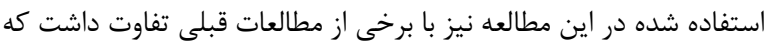

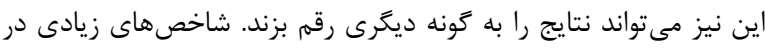

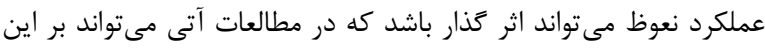

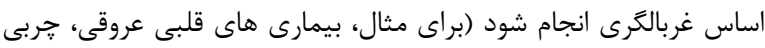

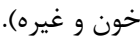

تشكر و قدردانى: بدينوسيله از جناب آقاى دكتر ابوطالب صارمى، آقاى دكتر محمد رضا ناطقى، سركار خانم نادرى و كاركنان محترم مركز

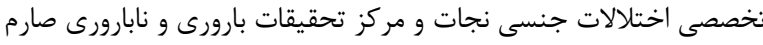

$$
\text { تقدير و تشكر به عمل مى آيد. تخدات }
$$

تاييديه اخلاقى: اين طرح مورد تاييد كميته اخلاق (IEC) مركز

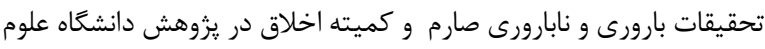

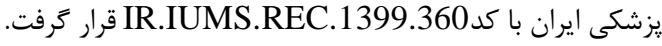

$$
\text { منارض منافع: در اين مطالعه تعارض منافع وجود نداشت. }
$$

منابع

1- Shamloul R, Ghanem H. Erectile dysfunction. The Lancet. 2013 Jan 12;381(9861):153-65.

2- Glina S, Shindel A, Eardley I, Ghanem H. Classic Citations: Cavernosal Alpha-Blockade: A New Technique for Investigating and Treating Erectile Impotence by GS Brindley. The journal of sexual medicine. 2008 Aug 1;5(8):1791-4.

3- Najari BB, Kashanian JA. Erectile dysfunction. Jama. 2016 Nov 1;316(17):1838-.

4- Yafi FA, Jenkins L, Albersen M, Corona G, Isidori AM, Goldfarb S, Maggi M, Nelson CJ, Parish S, Salonia A, Tan R. Erectile dysfunction. Nature reviews Disease primers. 2016 Feb 4;2(1):1-20.

5- Papagiannopoulos D, Khare N, Nehra A. Evaluation of young men with organic erectile dysfunction. Asian journal of andrology. 2015 Jan;17(1):11.

6- Kannan P, Winser SJ, Choi Ho L, Hei LC, Kin LC, Agnieszka GE, Jeffrey LH. Effectiveness of

\section{بحث و نتيجه كيرى}

در مطالعه حاضر به مقايسه اثربخشى تادالافيل خوراكى و بيوفيدبك

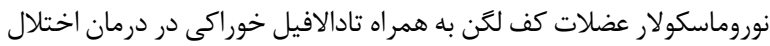

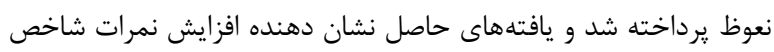

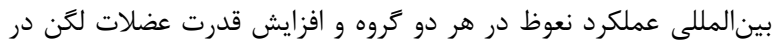

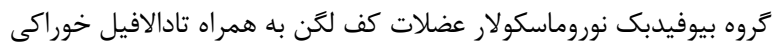
بود. اين اولين مطالعهاى است كه علاوه بر مصرف داروى تادالافيل نوريل همزمان از بيوفيدبك عضلات كف لكن هم در درمان اين اختلال استفاده شده است.

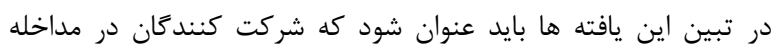

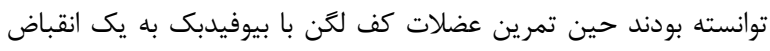

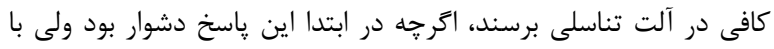

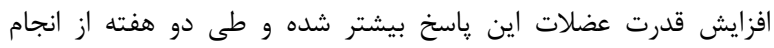

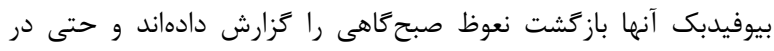

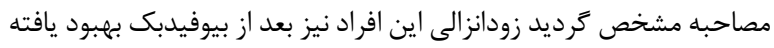

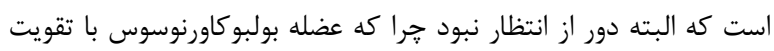

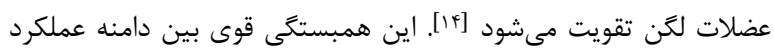

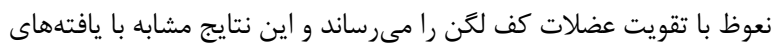

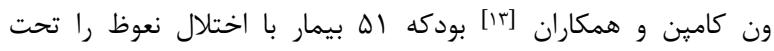

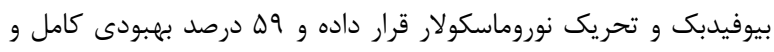

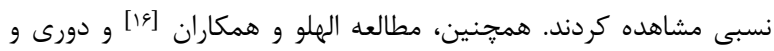

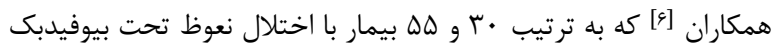

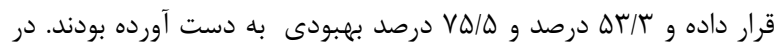

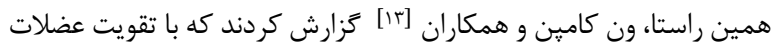

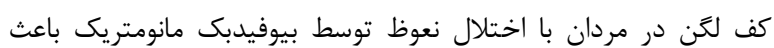
افزايش عملكرد نعوظ مى مردود

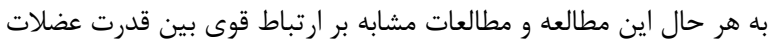

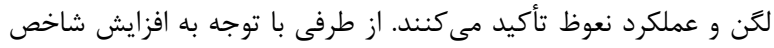

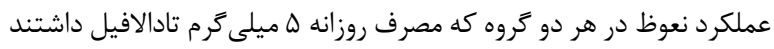

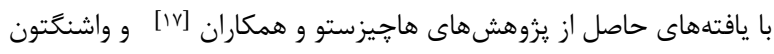

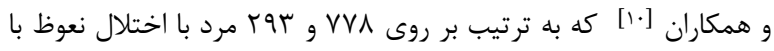

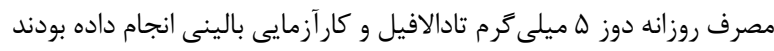

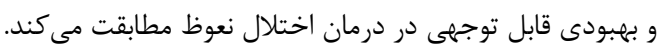

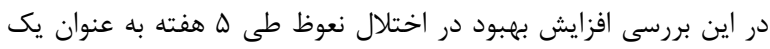

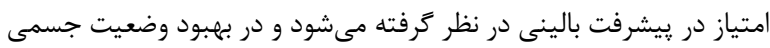

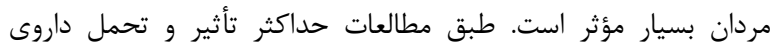

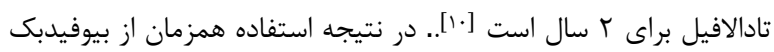

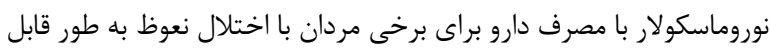

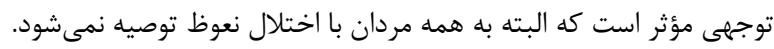

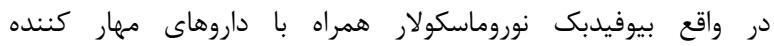

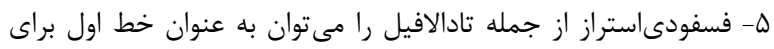

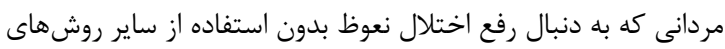


مقايسه اثربخشى تادالافيل خوراكى و بيوفيدبك نوروماسكولار عضلات كف لكن همراه با تادالافيل خوراكى در درمان اختلال نعوظ مردان 1 إ

Rheumatology and Rehabilitation. 2014 Oct 1;41(4):179.

17- Hatzichristou D, d'Anzeo G, Porst H, Buvat J, Henneges C, Rossi A, Hamidi K, Büttner H. Tadalafil $5 \mathrm{mg}$ once daily for the treatment of erectile dysfunction during a 6-month observational study (EDATE): impact of patient characteristics and comorbidities. BMC urology. 2015 Dec 1;15(1):111 physiotherapy interventions for improving erectile function and climacturia in men after prostatectomy: a systematic review and metaanalysis of randomized controlled trials. Clinical rehabilitation. 2019 Aug;33(8):1298-309.

7- Lavoisier P, Roy P, Dantony E, Watrelot A, Ruggeri J, Dumoulin S. Pelvic-floor muscle rehabilitation in erectile dysfunction and premature ejaculation. Physical therapy. 2014 Dec 1;94(12):1731-43.

8- Costa P, Grivel T, Gehchan N. Tadalafil once daily in the management of erectile dysfunction: patient and partner perspectives. Patient preference and adherence. 2009;3:105.

9- Coward RM, Carson CC. Tadalafil in the treatment of erectile dysfunction. Therapeutics and clinical risk management. 2008 Dec;4(6):1315.

10- Washington III SL, Shindel AW. A once-daily dose of tadalafil for erectile dysfunction: compliance and efficacy. Drug design, development and therapy. 2010;4:159.

11- Colpi GM, Negri L, Nappi RE, Chinea B, Colpi DG. Perineal floor efficiency in sexually potent and impotent men. International journal of impotence research. 1999 Jun;11(3):153-7.

12- Ibrahim IK, Hameed MM, Taher EM, Shaheen EM, Elsawy MS. Efficacy of biofeedback-assisted pelvic floor muscle training in females with pelvic floor dysfunction. Alexandria Journal of Medicine. 2015;51(2):137-42.

13- Van Kampen M, De Weerdt W, Claes H, Feys H, De Maeyer M, Van Poppel H, Baert L. Contribution of pelvic floor muscles exercises in the treatment of impotence (Doctoral dissertation, $\mathrm{PhD}$ thesis, Katholieke Universiteit Leuven, Belgium).

14- Dorey G, Speakman MJ, Feneley RC, Swinkels A, Dunn CD. Pelvic floor exercises for erectile dysfunction. BJU international. 2005 Sep;96(4):595-7.

15- Van Kampen M, De Weerdt W, Claes H, Feys H, De Maeyer M, Van Poppel H. Treatment of erectile dysfunction by perineal exercise, electromyographic biofeedback, and electrical stimulation. Physical Therapy. 2003 Jun 1;83(6):536-43.

16- Al-Helow MR, Abdul-Hady H, Fathalla MM, Zakaria MA, Hussein O, El Gahndour T. The role of biofeedback in the rehabilitation of venoocclusive erectile dysfunction. Egyptian 